\title{
Tracing the evolution of chiropractic students' confidence in clinical and patient communication skills during a clinical internship: a multi-methods study
}

Mark Hecimovich ${ }^{1 * \dagger}$ and Simone Volet ${ }^{2+}$

\begin{abstract}
Background: Anecdotal evidence points to variations in individual students' evolving confidence in clinical and patient communication skills during a clinical internship. A better understanding of the specific aspects of internships that contribute to increasing or decreasing confidence is needed to best support students during the clinical component of their study.

Methods: A multi-method approach, combining two large-scale surveys with 269 students and three in-depth individual interviews with a sub-sample of 29 students, was used to investigate the evolution of change in student confidence during a 10-month long internship. Change in levels of confidence in patient communication and clinical skills was measured and relationship to demographic factors were explored. The interviews elicited students' accounts and reflections on what affected the evolution of their confidence during the internship.

Results: At the start of their internship, students were more confident in their patient communication skills than their clinical skills but prior experience was significantly related to confidence in both. Initial confidence in patient communication skills was also related to age and prior qualification but not gender whilst confidence in clinical skills was related to gender but not age or prior qualification. These influences were maintained over time. Overall, students' levels of confidence in patient communication and clinical skills confidence increased significantly over the duration of the internship with evidence that change over time in these two aspects were inter-related. To explore how specific aspects of the internship contributed to changing levels of confidence, two extreme subgroups of interviewees were identified, those with the least increase and those with the highest increase in professional confidence over time. A number of key factors affecting the development of confidence were identified, including among others, interactions with clinicians and patients, personal agency and maturing as a student clinician.
\end{abstract}

Conclusion: This study provides insight into the factors perceived by students as affecting the development of professional confidence during internships. One particularly promising area for educational intervention may be the promotion of a pro-active approach to professional learning.

\footnotetext{
* Correspondence: m.hecimovich@murdoch.edu.au

${ }^{\dagger}$ Equal contributors

'School of Chiropractic and Sports Science, Murdoch University, Murdoch,

Western Australia

Full list of author information is available at the end of the article
} 


\section{Background}

The internship is integral to most manual therapy programs, for example physical therapy, chiropractic, athletic training and osteopathy, and is often the first time students are exposed to real patients in a supervised, clinical situation. One of the main aims of the internship is to provide students with multiple opportunities to integrate theoretical knowledge with practical skills [1], while receiving ongoing guidance and feedback. Students are expected to record patient history, assess and treat patients, and provide counseling on a myriad of issues such as correct lifting and bending techniques, and exercise. Research shows that internships increase clinical competence, promote socialization within the profession, foster the development of a positive self-image, and promote professional confidence [2]. Furthermore, internships enable the collaboration of educators and mentors in facilitating the transition of the student to professional practitioner [3].

There is evidence to suggest that the internship is more significant than other learning opportunities, such as lectures and labs, in the building of confidence during a student's tertiary experience, on the grounds that confidence increases with the experience gained through clinical exposure. Although this is well supported by the literature [4-7], there is evidence this may not always be the case. During the internship component students come face to face with inherent complexities of clinical practice, and the way in which these are navigated can vary significantly among students. For example, some students may possess high levels of perceived confidence prior to commencing their clinical rotation, only to find the reality of practice confronting and therefore experience a sudden reduction in confidence [8]. Alternatively, there may be peaks and troughs during internship, based upon continuous challenges that are sometimes successfully met but at other times lead to frustration [9]. Of particular concern for educators are the students who express confidence in procedures that they have had little experience in clinical settings [10]. Research on this phenomenon has highlighted the way in which students who are over-confident about their abilities can be a potential danger to patients [11].

To date, there is a paucity of empirical research in the development of confidence in clinical skills and patient communication in the field of manual and manipulative therapy. Research into the evolution and conditions of change in students' professional confidence in manual medicine programs requires not only psychometrically reliable measures, but also measures with high levels of validity in a supervised clinical setting. Furthermore, in order to measure change in levels of confidence over a period of time, the instruments must be sensitive enough to capture the levels of change in confidence that can reasonably be expected during an internship. If one of the goals of the internship is to provide an environment that increases confidence alongside competence in clinical skills and patient communication, then developing a better understanding of how confidence evolves during the internship is imperative. Moreover, the factors that lead to either increased or decreased confidence need to be better understood.

This issue has been addressed by the study reported in this paper. The aims of the research were to: 1) measure initial and changing levels of confidence in students' clinical and patient communication skills over the duration of an internship, with the consideration of the potential influence of gender, age, prior experience within the profession, and qualifications upon entry into the program; and 2) determine which specific aspects of the internship contributed to increasing or decreasing confidence in clinical skills and patient communication, from students' own perspective.

\section{Methods}

\section{Programs and participants}

Participants $(n=269)$ were from seven different chiropractic programs, five located in the United States and two in Australia, enrolled in their clinical internship in 2006 and 2007. All programs had been selected due to similar curricula and clinical experience, which provided similar professional experiences for students. For example, the first two years consists of basic science units such as anatomy, biology, chemistry, physiology, biochemistry, immunology, genetics and microbiology. This followed by two to three years of clinical units such as biomechanics, nutrition, pharmacology, orthopedics, neurology, manipulative techniques, physical examination procedures, radiology and clinical internship. Human ethics approval and student consent were obtained from all cohorts before the study began.

\section{Procedures and instruments}

A multi-method approach, combining two large-scale surveys (beginning and end of internship) and three indepth individual interviews with a sub-sample of 29 students from a single cohort were used to investigate the evolution of change in student confidence in clinical skills and patient communication over the duration of the internship, and the factors that may influence the evolution of confidence during the internship, from students' experiential perspective.

\section{Instrument to measure confidence in clinical and patient communication skills}

The instrument, developed by the authors, used [unpublished data under review, Hecimovich, Styles, Volet] for measuring self-assessed confidence in these two aspects 
of professional confidence consists of two scales, each capturing the multi-faceted nature of the target construct:

\section{Patient Communication Confidence Scale (PCCS): 28 items \\ 2. Clinical Skills Confidence Scale (CSCS): 27 items}

Demographic information regarding age, gender, prior relevant experience, and level of qualification upon entry into the program was also collected, to investigate predictors in initial levels of confidence, and possible impact on further development of confidence.

The PCCS and CSCS are customized to the supervised clinical setting, and therefore measure students' selfassessed levels of confidence in patient communication and clinical skills in relation to interactions with real patients during the clinical internship. The items presented as questions, are formulated to capture real-life experiences students are most likely to encounter with patients during their internship. Issues range from general to specific, for example, from how confident students felt in discussing general health issues with patients to performing basic and very specific physical examination procedures. Sample items include, "How confident are you in your ability at discussing personal and/or sensitive issues with new patients?" and, "How confident are you in your ability to perform basic physical examination procedures such as blood pressure, pulse and respiration rates on a patient?" Response categories were presented in a six-point Likert-style response format from 1 to 6 , from "not confident at all" to "very confident". There are no reverse items.

The psychometric properties of the two scales PCCS and CSCS were established through comprehensive psychometric analysis based on the Rasch measurement model $[12,13]$, using the software program, RUMM2020 developed by Andrich et al [14]. The two scales were found to be valid and reliable measures of confidence with high Person Separation Indices (0.96 for PCCS; 0.93 for SCSC), which are equivalent of Cronbach's alpha statistics. Through the Rasch analyses, each scale is standardized with a mean of zero, thus the generation of positive and negative scores for individuals. Data from beginning and end surveys were analysed together to obtain beginning and end scores based on the same hierarchical response scale.

To address validity, two existing valid and reliable scales - the General Self-Efficacy scale (GSE) and the Personal Report of Communication Apprehension scale (PRCA-24) - were included in the battery of tests. The GSE scale measures feelings of mastery in various situations, providing evidence of generalised self-efficacy among students. Previous research shows the GSE is a reliable scale with convergent and discriminant validity, with alpha reliability coefficients ranging from .75 to .90 $[15,16]$. The PRCA-24 scale measures feelings about communicating with others. However, only one subcategory (interpersonal communication) was used in this study, as the other sub-categories are not typically encountered in clinical contexts. Prior research has demonstrated content, criterion and construct validity of the PRCA-24 [17]. Results showed a positive correlation between confidence scores for clinical and patient communication skills and general self-efficacy, and a negative correlation between confidence scores for patient communication and interpersonal communication, indicating significant associations between the new and existing scales and add to the evidence of the validity of the new scales.

Analyses of variance (ANOVAs) were used to examine the extent to which students' initial levels of confidence in clinical and patient communication skills were related to age, gender, prior experience or possession of a first degree, with possible interaction between factors. Change in levels of confidence in clinical and communication skills was investigated using multiple analyses of variance (MANOVA) with repeated measures for time.

\section{Interviews}

In addition to completing the beginning and end of internship surveys, 29 students from the same program gave their consent to participate in three semistructured individual interviews, conducted at regular intervals over the 10-month duration of their internship: stage 1 at months one or two; stage 2 at months five or six; and stage 3 at months nine or ten. These interviews were conducted in an informal, conversational style. The main purpose was to elicit students' reflections on what may have contributed to increasing or decreasing their confidence during their internship. An example of question to prompt reflection was, "Has there been anything recently which has helped or hindered your confidence in being able to communicate with a patient?", which was followed up by probes to obtain more in depth responses. All interviews were transcribed.

A thematic analysis of the interview data was undertaken to identify key factors that impact self-confidence in patient communication and clinical skills. Thematic analysis is delineated as a qualitative analytic method that is utilized for identifying, analyzing and reporting themes with data [18]. It comprises several phases. The first phase consisted of reviewing the sets of transcripts after the interviews several times and observing for meanings and emerging patterns. The second phase involved coding and the production of initial (open) codes. The third phase involved the process of axial coding, whereby all data was initially coded, a list of 
different codes was developed, these different codes were sorted into potential themes, and relevant extracts of coded data were then collated under the identified themes. The fourth and fifth phase involved reviewing, refining and naming the different themes that were identified during initial (open) and axial coding, and then developing a 'thematic map' and assessing whether it reflected the meanings evident in the data set as a whole. In this research, the 'thematic map' contained the various themes that affected student professional selfconfidence and emphasized aspects of these themes that were helpful or a hindrance.

\section{Results}

Confidence in clinical and patient communication skills prior to internship, overall and in relation to demographic factors

Overall students appeared more confident in their patient communication skills ( $\mathrm{PC}, \mathrm{M}=1.31, \mathrm{SD}=1.87$ ) than in their clinical skills (CS, $\mathrm{M}=0.55, \mathrm{SD}=1.08$ ) before starting the internship. The correlation coefficient between the two scales was $r=.68(p<.001)$, showing that confidence in patient communication and confidence in clinical skills were inter-related, and may form an overarching construct of professional confidence.

The extent to which the demographic factors were related to initial levels of confidence was examined separately for patient communication and clinical skills. Table 1 displays the breakdown in levels of confidence by gender, age, prior experience and prior qualification for patient communication (PC). As can be seen, confidence in patient communication was significantly related to age, prior experience and prior qualification but not to gender. While the relationship with prior experience and prior qualification would be expected in the area of patient communication, the relationship with age was not expected. Comparing the three age groups shows that confidence increased as age increased. All tests statistics are displayed on the right hand side of the table and the results of post-hoc comparisons using Bonferroni are at the bottom.

Table 2 displays the breakdown in initial levels of confidence for the same demographic factors for clinical skills (CS). As expected and like for patient communication, prior experience was significantly related to levels of confidence in clinical skills. However, and in contrast to patient communication, there was no relationship with age or prior qualification, suggesting that communication skills may be transferable across situations whereas clinical skills are not. Results of the statistical analyses and post-hoc comparisons using Bonferroni are showed respectively on the right hand side and at the bottom of the table.

\section{Change in confidence in patient communication and clinical skills over the duration of the internship}

Students' levels of confidence in patient communication (PC) skills and clinical skills (CS) increased significantly over the duration of the internship. The means, standard deviation, and results of paired t-tests for both patient communication (PC) and clinical skills (CS) are displayed in Table 3.

To determine if change in levels of confidence in patient communication and clinical skills were related to each other, 'difference' scores were computed, for both measures and correlated. The high correlation coefficient between the two change measures, $r=0.72$, $\mathrm{p}<.001$ showed that change over time in these two aspects of professional confidence were inter-related.

The extent to which change over time in PC and CS was influenced by demographic factors was examined next. A series of multiple analyses of variance (MANOVA) with repeated measures for time were carried out, with in turn experience, age, gender and qualification as the independent variable. Table 4 displays the results of these analyses.

As can be seen in Table 4, no interaction effects were found between any of the independent variable and time as the repeated measure. A number of significant main effects were found for the four independent variables, all of them consistent with the analyses conducted at the start of the internship. In other words, all the demographic factors identified as influencing students' levels of confidence in PC and CS at the beginning of the internship were found to be significant in students' further development of professional confidence over time.

While the enduring influence of prior experience, and to some extent qualification and age, on confidence development in patient communication skills could be expected, the sustained gender differences on the development of confidence in clinical skills deserve some attention.

Although overall levels of confidence increased significantly over the duration of the internship for both patient communication and clinical skills, there were large individual differences in the degree of increase. For some students, only a limited increase was observed while others displayed a dramatic increase. Possible reasons for these differences were explored in the interviews.

\section{Interviews}

The purpose of the interviews was to determine which specific aspects of the internship contributed to increasing or decreasing confidence in clinical skills and patient communication throughout the internship, from students' own perspective. For a synopsis of the aspects, 
Table 1 Initial confidence in patient communication skills broken down by demographic factors

\begin{tabular}{|c|c|c|c|c|c|}
\hline Factor & Group & $\mathbf{N}$ & Mean(std dev) & $F$ statistic & $p$ value \\
\hline \multirow[t]{2}{*}{ Gender } & Male & 153 & $1.38(1.88)$ & .598 & $p=.44$ \\
\hline & Female & 116 & $1.21(1.75)$ & & \\
\hline \multirow[t]{3}{*}{ Age } & $20-25$ & 136 & $0.97(1.50)$ & 4.934 & $p=.008$ \\
\hline & $26-35$ & 106 & $1.63(1.95)$ & & \\
\hline & $36+$ & 27 & $1.78(2.43)$ & & \\
\hline \multirow[t]{6}{*}{ Experience } & None at all & 48 & $1.19(2.00)$ & 3.626 & $p=.003$ \\
\hline & & 63 & $0.71(1.19)$ & & \\
\hline & & 56 & $1.11(1.83)$ & & \\
\hline & & 54 & $1.71(1.90)$ & & \\
\hline & & 25 & $2.10(2.14)$ & & \\
\hline & Extensive & 23 & $1.90(1.77)$ & & \\
\hline \multirow[t]{2}{*}{ Qualification } & Possess degree upon entry & 153 & $1.53(1.93)$ & 5.16 & $p=.024$ \\
\hline & No degree upon entry & 116 & $1.02(1.64)$ & & \\
\hline
\end{tabular}

Post-hoc comparisons by Age using Bonferroni revealed a significant difference ( $p=.017$ ) between the 20-25 and 26-35 age groups. Post-hoc comparison by Experience using Bonferroni revealed a significant difference between level 2 and level $4(p=.044)$ and level $5(p=.016)$.

please consult Table 5. To explore this issue, two extreme sub-groups of students from the same instructional context $(n=106)$ were identified on a normative basis determined by the questionnaire data: a sub-group displaying the greatest increase (PC: 2.77 - 4.8; CS: 1.79 - 1.98) and a sub-group displaying the least increase (PC: - 0.3 - 1.02; CS: .10 - 1.18) in confidence. Using this normative approach, students were categorized in the high increase category if their score on PC or CS increased from being located in the lower to mid $33 \%$ at the beginning of the internship to the upper $33 \%$ at the end of the internship, and reciprocally, in the low increase category if their score on PC or CS went from the upper to the middle $33 \%$ at the beginning of the internship to the lower $33 \%$ at the end.

Of the 106 students, 24 displayed a high or a low increase in confidence in either $\mathrm{PC}$ or $\mathrm{SC}$ or both. Of these 24 students, 12 had been interviewed. By chance six students fell into the high increase category, PC $(\mathrm{n}=3)$ or $\mathrm{CS}(\mathrm{n}=2)$ or both $(\mathrm{n}=1)$, and six students into the low increase category, PC $(n=3)$ or CS $(n=0)$ or both $(\mathrm{n}=3)$. Hereafter, students are identified as Low Incr PC, Low Incr CS, High Incr PC, High Incr CS, preceded by their research id, and followed by the stage of their internship and page number of the interview transcript.

Table 2 Initial confidence clinical skills broken down by demographic factors

\begin{tabular}{|c|c|c|c|c|c|}
\hline Factor & Group & $\mathrm{N}$ & Mean(std dev) & $F$ statistic & $p$ value \\
\hline \multirow[t]{2}{*}{ Gender } & Male & 153 & $0.31(1.04)$ & 4.839 & $p=.029$ \\
\hline & Female & 116 & $0.03(1.05)$ & & \\
\hline \multirow[t]{3}{*}{ Age } & $20-25$ & 136 & $0.11(0.95)$ & .861 & $p=.424$ \\
\hline & $26-36$ & 106 & $0.29(1.19)$ & & \\
\hline & $36+$ & 27 & $0.18(0.99)$ & & \\
\hline \multirow[t]{6}{*}{ Experience } & None at all & 48 & $0.12(1.08)$ & 2.639 & $p=.024$ \\
\hline & & 63 & $-0.06(0.89)$ & & \\
\hline & & 56 & $0.02(0.96)$ & & \\
\hline & & 54 & $0.44(1.15)$ & & \\
\hline & & 25 & $0.45(1.28)$ & & \\
\hline & Extensive & 23 & $0.58(0.92)$ & & \\
\hline \multirow[t]{2}{*}{ Qualification } & Possess degree upon entry & 153 & $0.27(1.12)$ & 1.910 & $p=.168$ \\
\hline & No degree upon entry & 116 & $0.09(0.89)$ & & \\
\hline
\end{tabular}

Post-hoc comparison by Experience using Bonferroni revealed none had significant difference. 
Table 3 Means, standard deviation and results of paired t-tests for both patient communication (PC) and clinical skills (CS) at the beginning and end of the clinical internship

\begin{tabular}{|c|c|c|c|}
\hline & Beginning of clinical internship & End of clinical internship & Paired t-tests \\
\hline & Mean (std dev) & Mean (std dev) & $p$ value \\
\hline Patient communication skills & $1.21(1.77)$ & $2.72(1.92)$ & $t(207) 13.86, p<.001$ \\
\hline Clinical skills & $0.06(0.99)$ & $1.12(1.18)$ & $t(207) 15.07, p<.001$ \\
\hline
\end{tabular}

\section{Key factors influencing the development of confidence in clinical skills}

Although the researchers' intent was to gain a better understanding of the factors, influencing confidence in a broad range of clinical skills, including physical examination and manipulative procedures, it turned out to be the manipulative procedures, or adjustments, which students mainly focused upon. Four key factors were identified: Encounters with clinicians; audible noise; perceived poor skills, and; personal agency.

1. Interaction with clinicians Encounters and the interaction with clinicians, a significant factor for all students in both groups was found to be a central issue for students during stage 1 interviews. Clinician feedback was reported as a key element in their encounters with clinicians.

Some of the clinicians just come in and they see what you're doing and then just go back out and don't really give you feedback. Or some clinicians come in and because I cannot perform the adjustment they take over and then just walk back out and don't say anything. So those don't make me feel very confidence.
It feels as though I've failed ... On the other hand some clinicians come in and I can't get the adjustment and they actually set up on the patient and show me and teach me how to do it.

(10, High Incr CS, stage 1, p24)

Their influence continued to be a factor as the students progressed through the internship, with feedback still being a key element, What I have found really helpful is the clinician really saying, "OK. You need to do this." "You need to take a more lateral flexion." Or see me setting up on them (but) it just hasn't translated into my confidence levels. (8, High Incr CS, stage 2, p5). It would be feedback from clinicians, because it seems as they're the one that's sort of assessing or marking or supervising us and whenever I get a good feedback from a clinician I would feel as though I've improved and that would increase my confidence. (10, High Incr CS,, stage 3, p12). However, during the later stages personality issues were also being brought forth.

I don't have a problem with cervicales when there is no clinician watching me. I just get nervous in front of clinicians. It is sort of like you wanted to perform

Table 4 MANOVA Main effects for time, age, gender and qualification

\begin{tabular}{|c|c|c|c|}
\hline \multirow{2}{*}{$\begin{array}{l}\text { MANOVA analysis } \\
\text { Category }\end{array}$} & \multicolumn{3}{|c|}{$\begin{array}{c}1 \text { vs } 3(n=208) \\
10 \text { month internship }\end{array}$} \\
\hline & Interaction effect & $\begin{array}{l}\text { Main for time as } \\
\text { (repeated factor) }\end{array}$ & $\begin{array}{l}\text { Main for experience, age, } \\
\text { gender or qualification }\end{array}$ \\
\hline \multicolumn{4}{|l|}{ Experience by time } \\
\hline PCCS & $p=.329$ & $p=.000$ & $p=.000$ \\
\hline CSCS & $p=.580$ & $p=.000$ & $p=.008$ \\
\hline \multicolumn{4}{|l|}{ Age by time } \\
\hline PCCS & $p=.331$ & $p=.000$ & $p=.003$ \\
\hline $\operatorname{CSCS}$ & $p=.264$ & $p=.000$ & $p=.219$ \\
\hline \multicolumn{4}{|l|}{ Gender by time } \\
\hline PCCS & $p=.476$ & $p=.000$ & $p=.242$ \\
\hline CSCS & $p=.962$ & $p=.000$ & $p=.001$ \\
\hline \multicolumn{4}{|l|}{ Qualification by time } \\
\hline PCCS & $p=.702$ & $p=.000$ & $p=.038$ \\
\hline $\operatorname{cscs}$ & $p=.657$ & $p=.000$ & $p=.145$ \\
\hline
\end{tabular}


Table 5 Synopsis of factors influencing the evolution of confidence in clinical skills and patient communication

\begin{tabular}{|c|c|}
\hline \multicolumn{2}{|c|}{ Factors and stages in which they appeared } \\
\hline Clinical skills & Patient communication \\
\hline Interaction with clinicians (stages $1,2,3$ ) & Meet and greet the patient (stage 1) \\
\hline $\begin{array}{l}\text { A help and hindrance with verbal (positive } \\
\text { and negative comments) and non-verbal } \\
\text { (demonstrating skill) feedback being key elements }\end{array}$ & $\begin{array}{l}\text { Allowing students to initiate meeting and } \\
\text { greeting the patient provides them to make a } \\
\text { quick and helpful initial assessment }\end{array}$ \\
\hline Audible noise (stage 1, 2, 3) & Interaction with clinicians (stage 1, 2, 3) \\
\hline $\begin{array}{l}\text { Students relying on this as an indicator of success; } \\
\text { forgoing other indicators such as } \\
\text { pain, range of motion, activities of daily living }\end{array}$ & Non-challenging conditions (stage $1,2,3$ ) \\
\hline Perceived limited skills (stage 2, 3) & $\begin{array}{l}\text { Patient conditions which do not challenge the } \\
\text { student limits their ability to mature }\end{array}$ \\
\hline $\begin{array}{l}\text { Linked with lack of audible obtained } \\
\text { with manipulation }\end{array}$ & Personal agency (stage 2, 3) \\
\hline Personal agency (stage 3) & Maturing as a student clinician (stage 2,3 ) \\
\hline \multirow[t]{5}{*}{$\begin{array}{l}\text { Students seeking way to improve is an } \\
\text { indicator of maturity }\end{array}$} & $\begin{array}{l}\text { Building rapport with patients and recognizing } \\
\text { why they seek care }\end{array}$ \\
\hline & Patient conflicts (stage 3 ) \\
\hline & $\begin{array}{l}\text { Lack of maturity and personal agency result in } \\
\text { poor patient encounters }\end{array}$ \\
\hline & Perceptions of the profession (stage 3) \\
\hline & Questioning the profession \\
\hline
\end{tabular}

but it is too much pressure. There are clinicians that I have felt at ease straight away.

(11, High Incr CS, stage 3, p12)

There are clinicians who have strong personalities who I also don't approach. They're pushy and forceful. They enforce their ideas upon you or suggest something. . that would probably be the biggest thing. (6, Low Incr CS, stage 3, p19)

\section{Audible noise}

Another influencing factor (positive or negative) identified in the first few months was the audible, popping or cracking, noise given off during a manipulative procedure, which students used as a way to measure success in the skill. Interestingly, only those whose confidence rose significantly identified this during the first interview stage.

Not very (confident), because I haven't been getting a lot of my adjustments. (This has affected your confidence?) Sort of or more like I feel why can't I get it and they can get it. (What does, 'get it', mean?) The audible. (So would it be success, audible means success?) Yes. (10, High Incr CS, stage 1, p22)

This factor became more central for both groups at the time of the stage 2 interviews, a lack of experience of achieving a cavitation in that joint. Lack of success (8, High Incr CS, stage 2, p4). One student specified that while other outcomes such as reduction of pain were important, the audible remained the key element of success, I like the patient out of pain but I guess hearing the release (audible) is probably the most gratifying. (11, High Incr CS, stage 2, p13). ... success rate...(How do you measure success?) If you get an audible. (6, Low Incr CS, stage 2, p21).

Towards the end of the internship, only students with limited increase in confidence identified the audible as a factor. The placebo effect of the audible was perceived as beneficial for them and the patient.

A lot of it's to do with how much success you have, which means knowing you moved the right joint or I guess getting a noise out of the joint's always a good indication.. That's an indication to the patient as well and I guess that's the, you know if you got the audible and the patient know you got it as well. (6, Low Incr CS,stage 3, p13)

3. Perceived limited skills

As students progressed through the internship, those with limited increase in confidence perceived their limited manipulation skills as a hindrance to confidence. This perception lead them to doubting themselves in the latter half of the internship. 
My body doesn't like to co-ordinate the side-posture drop thrust. I am just not that good at doing them because I am not good at the drop thrust. (3, Low Incr CS, stage 2, p7)

Lumbar manipulation is the same since January (beginning of internship).....I'm very hesitant because I feel like I'm floundering and I don't know what's going to happen so when I try to make the adjustment and that's my biggest concern or what stops me trying to do it is. ...it sounds vain or silly but I just don't want to look stupid in front of the patient. (4, Low Incr CS, stage $3, \mathrm{p} 1$ )

I've got a few patients which are pretty tough to adjust at the moment and sometimes I don't give myself a chance. When they come in for another visit and I know they're hard to adjust, you know, I'm going, "ah, not going to get this..." (6, Low Incr CS, stage 3, p19)

\section{Personal agency}

In contrast, the latter half of the internship saw those who had significant increase in confidence in manipulative skills become more proactive. They displayed personal agency by seeking ways to improve their skills and a mature approach to perceived failure.

I've been asking around for more people to correct me and going to the technique lab. This has helped (10, High Incr CS, stage 3, p8).

I don't have the same hang up that I had at the beginning of the year, which was such a big thing. If I can't adjust now . . . because I do know that I can adjust, like I can't adjust this patient but the next one that I get I can adjust. I feel quite happy about that. (8, High Incr CS, stage 3, p9)

In contrast, those students with limited increase in confidence also reflected on the influence of the clinician but instead of seeking ways to improve, they displayed self doubt which inhibited taking action.

\section{Patient communication}

Various factors influenced student confidence in patient communication as they progressed though the internship. Similar to the reflections on clinical skills, the clinicians played a major role in their confidence. Those students whose confidence rose significantly became more proactive and matured as clinicians while the other group struggled with clinician and patient conflicts and with the profession's identity. Seven factors were identified as influencing confidence in patient communication.
1. Meet and greet the patient Meeting and greeting the patient in the waiting room, as opposed to the clinician doing this, was identified as a factor in the early stages. For students, this helped them understand the patient's condition and therefore boosted confidence. Because you can see how they rise from a chair and you can kind of do a very quick initial assessment (7, High Incr PC, stage 1, p9).

I had to walk up to them and take them down into the room whereas normally we're already sitting with all our diagnostic kits laid out we're sitting there we don't even have a clip board yet but we're sitting there and we're just waiting for the clinician to walk down with the patient and the clinician usually makes the introduction as well. (7, High Incr PC,

stage 1, p8)

2. Interactions with the clinicians

The nature of the interactions between student and clinician was brought forth as a significant factor in confidence for all students. These interactions contributed to boosting or hindering confidence in the early stages on the internship.

I'm not saying this is a good or bad thing on any of the clinicians, but when they don't treat you like equals, sort of give you advice rather than say well you should have been doing this. Sort of go what I would have done, and you know you could have done this and not sort of degrade you. (9, High Incr PC, stage 1, p26-27)

Ones that aren't going to shoot you down are going to build your confidence. It's not so much tone of voice but if you've got something written down on a piece of paper, you know if they turn around and say what have you been doing for the past five years, that's just going to blow your confidence. (6. Low Incr PC, stage 1, p20)

As the internship progressed, those whose confidence rose significantly relied less on the clinicians, but the other group continued to reflect on how interaction with the clinicians affected their confidence in a positive way, to hear that from a clinician made a difference...but coming from a clinician boosts your confidence more (6, Low Incr PC, stage 2, p3-4), but also in a negative way.

There are a couple of clinicians which seem a little bit harsher. They're just asking questions as if they're out to get you or something. There's definitely clinician avoidance happening. (1, Low Incr PC, stage 2, p16-17) 
The significance of clinician interactions continued to be a factor within this group even into the latter stages of the internship.

I think I rely too much on the backup with the clinicians and perhaps should be distances myself from them ... As stated before I feel that I'm better at it when they're not in the room because I'm just more confident. ... it's like I want their approval that I'm saying the right thing. (1, Low Incr PC, p9, stage 3, p12)

... for the past two months the clinicians give the fifth years more freedom ,.. it is probably a subconscious kind of fear like I don't want to make mistakes in front of clinicians. The clinicians are very helpful. Maybe I should get that away from my brain, and start thinking that they are more experienced. (2, Low Incr PC, p6, stage 3, p18)

3. Non-challenging patient conditions Students with limited increase in confidence identified non-challenging patient conditions as being a confidence boost in the early stages of the internship, If it's musculoskeletal I feel quite confident. But if it comes to something else, say stomach or thyroid, it drops (2, Low Incr PC, stage 1, p3).... it comes down to what the complaint is, if it's easy to explain. If it's hard to explain then you get more worried. (6, Low Incr PC, stage1, p20)

As students progressed through the internship, difficult cases challenged their confidence in communicating with patients,

I haven't had anything that has been too curly if you know what I mean. . so that may well change when I get a patient come through that's maybe got something a little more serious... . if a patient came in and I found out the prognosis wasn't so good, that may affect my communication right there and then...therefore affect my confidence as well (5, Low Incr PC, stage 2, p2-3). By the latter stages this continued, It is not like I wouldn't be able to communicate but my confidence level would be a 6/6 of mechanical low back and maybe 3/6 for a strange arthridity. So there's an influencing factor on confidence (2, Low Incr PC, stage 3, p7)

4. Personal agency

Approximately five to six months into the internship students who had significant increases in patient communication confidence displayed proactive ways of improving their communication skills.
It (patient history) was one that I recorded so it was good to go back and watch and to critique that so I've got to work on this, this, and this and I think that was really a good learning experience. I've been consciously working on that and I think it's made a difference. I'm glad I did because it showed a few things that I didn't realise I did. (9, High Incr PC, stage 2, p20)

I've modified my communication in that I've had to be a lot more direct. I realised I was just talking too long, there was too much unnecessary information that is being put out in the open; probably clouding a little bit of my memory and judgment as well. I've really pulled back on using some colloquialisms because a couple of clinicians have said be less colloquial, but not too technical. (7, High Incr PC, stage 3, p19-20)

5. Maturing as a clinician

Those students whose confidence rose significantly and had developed personal agency also started to mature as clinicians. What helped boost their confidence was their ability to build rapport with their patients,

I think it (confidence) has gotten a little bit higher because I've built a good rapport with my patients, I tend to remember what they did, like what they were telling me that they were going to do on the weekend, so I will ask them what they did on the weekend when they came in. (7, High Incr PC, stage 2, p13). These students also recognized patient action and interaction as a significant boost in their confidence to communicate.

For them to go "ok if that's what you think I need then that's what we'll do". ....gives you a bit of confidence to say this complete stranger that I've met an hour and a half ago has just trusted me that I need to this, this and this. It's a confidence boost. (9, High Incr PC, stage 3, p11).

6. Patient conflicts

In contrast, many students with limited increase in patient communication confidence expressed personality conflicts with patient during the latter stages of their internship,

(My confidence in patient communication is) Less with new patients because you don't know what their personality is, some patients are quite standoffish (3, Low Incr PC, stage 3, p2).

Some projected blame onto the patient, something has hindered (my confidence) but that's based on a patient. I found it very difficult to control the history. I'd ask a question and I would be there 
for the next ten minutes listening and I'd try an jump in there and you know I'd try and take control and he just wouldn't stop. (6, Low Incr PC, stage 3, p16).

\section{Perceptions of the profession}

Some aspects of the chiropractic profession were found difficult for students with a limited confidence increase. While this emerged only in the latter stage of the internship, it seemed to affect some students' ability to confidently communicate with patients.

Yeah, I've become more and more confused in the chiropractic paradigm. I don't know if any other profession has such difficulty explaining what they personally do. I mean you go to the dentist, the dentist says, I do this to your teeth. You go to the chiropractor, what does a chiropractor actually do. So I have trouble summarising it to an answer that wouldn't go something like "are you sure that that has evidence?" So I try to combine perspectives and I end up with a lot of "it might be, but maybe."I doubt myself when I phrase it. I'd like something more solid. (3, Low Incr PC, stage 3, p8)

The only problem is my own demons. ...I'm still not quite sure how much I believe in chiropractic so this is my biggest block. .....I don't feel confident in or I feel disappointed I can't convey confidence to my patients. I think they pick up on really confident (doctors). (4, Low Incr PC, stage 3, p4)

The factors identified by students as influencing the evolution of their confidence in patient communication and clinical skills are further discussed below, with some educational implications.

\section{Discussion}

One of the aims of the study was to identify how levels of confidence in students' clinical and patient communications skills evolved over the duration of an internship in relation to selected demographic factors. The survey data revealed that prior experience was significantly related to initial and evolving levels of confidence in both patient communication and clinical skills. In contrast, gender, age and prior qualification were related to the development of either clinical or patient communication skills.

The relationship between initial confidence and prior experience was expected, and is consistent with Schunk's [19] claims that exposure to models can instill selfbeliefs that influence individuals' subsequent course of action. Yet the finding that the sub-group of students with no prior experience displayed higher levels of confidence than those with moderate experience may indicate overconfidence, a concerning phenomenon which is discussed extensively in the literature [20].

The finding that male students rated their confidence in clinical skills higher than female students is consistent with evidence of females tending to underestimate their abilities [21] while their male counterparts overestimate their abilities [22]. This is consistent with those found in other fields, such as confidence in physics and computing [23,24]. According to Beyer \& Bowden [21], confidence may differ between genders due to the type of skill or task involved. They found that females consider themselves equally competent (high level confidence) when tasks are perceived as gender-neutral or (traditionally) 'feminine-type' skills (e.g. verbal or interpersonal) and underestimate their abilities in (traditionally) 'masculine-type' skills or occupations. This was demonstrated in studies with medical students [25-27], where female students underestimated their surgical skills, possibly due, according to the researchers, to the perceived notion of surgeon as a (traditionally) 'masculine' occupation. A similar perception may have contributed in explaining the findings in the present study. Some of the clinical skills utilized in manual medicine, such as joint manipulation, possibly being perceived as more physical and therefore 'masculine'.

The significant relationship between age or a prior degree and initial levels of confidence in patient communication skills, may indicate that interpersonal communication is a generic skill acquired through life experience and transferable to professional situations. In contrast, the lack of relationship between these two factors and confidence in clinical skills is consistent with those skills being highly specific to the profession. Interestingly, the sub-group of students in the highest age category tended to display lower levels of confidence in clinical skills than those in the mid age range. This might be due the myriad of issues that mature-age students face in their lives, which can lead to erosion in their confidence [28,29]. For example, in the field of health education, Feil et al [30] reported older medical students' sense of loss of previous personal and professional identity, and Donaldson and Graham [31] reported older students' frequent admission that they possess 'rusty study skills', low self-confidence and apprehension upon re-entering college.

The present study also aimed to examine the factors perceived by students as contributing to increase or decrease their confidence over time. The interview data with sub-groups of students, who demonstrated either a limited or a substantial increase in confidence, provided insight into the evolution of their confidence during the internship.

Interaction with clinicians and clinician feedback emerged as a prominent factor in the evolution of 
clinical and patient communication skills. The criticality of constructive feedback is well documented in the mentoring literature [32,33]. In the study, negative feedback was primarily reported as being in the form of verbal comments in which the students perceived the clinicians as putting them down and not treating them as peers, or taking over for the student and treating the patient. In contrast, positive feedback was verbal and non-verbal with clinicians providing supporting comments but also demonstrating how to perform a skill. This is consistent with Pitney and Ehlers [34] who stressed how mentor accessibility, approachability, and student initiative need to be enforced as these create an environment encouraging student participation and assist in the building of confidence [35].

Over time, students with high increases in confidence relied less on the clinicians while the other group continued to have mixed relationships with them. Some admitted relying too much on them while others still perceived them as being harsh in their approach. Interestingly, students displaying higher increases in confidence appeared more proactive and mature as student-clinicians, resulting in them relying less on clinician support. In contrast, those with low increases had not yet matured as student-clinicians. They continuously relied on clinicians, struggled with challenging patient conditions and patient conflicts and perceived limited skills. This is consistent with Bandura's [36] claim that self-efficacy, or confidence, is the foundation of human agency, since unless people believe they can produce desired effects by their actions, they have little incentive to act. This may explain why in this study, one sub-group had little incentive to seek ways to improve. More research is needed to fully understand this phenomenon.

A factor which was brought up by both sub-groups was the importance of the audible noise released from a manipulative procedure, as evidence of successful adjustment and with a direct effect on confidence, has received limited attention in the literature. Yet, according to Flynn et al [37], and Cleland et al [38], a joint audible can have a powerful placebo effect on both the patient and practitioner. This was demonstrated in this study, with some students attributing even more importance to the audible noise than patient outcomes as a measure of success. However, even if students focused on patient outcomes such as pain, range of motion and daily living activities, and minimized their confidence in the audible, they would still need to contend with the effect it has on patients. When their confidence is limited, they may struggle to communicate to their patients that the audible is not a representation of success.

Finally, some students' reflections on the chiropractic profession raises the broader issue of how students perceive their chosen profession and in this instance, chiropractic. However, the fact that only students with limited increases in confidence addressed this issue is noteworthy. A myriad of reasons may explain such perceptions but recent research involving non-practicing chiropractors [39] has pointed to chiropractic dogma and philosophy as reasons to abandon active practice.

There were a number of limitations that warrant attention. First, focusing on and measuring students in the chiropractic field may not be generalized to the full range of manual medicine programs, also including osteopathy, physiotherapy and athletic training fields. Second, the contextual scope of the qualitative (interview) data was limited to two separate student cohorts from a single university chiropractic program. These factors make it difficult to generalize the findings to other contexts and student experiences. Due to the small sample size, this study could not reliably relate interview findings and demographic factors, and therefore identify tendencies. Yet, such connections may exist and could be examined in future research. Also the research did not compare the impact of different clinical opportunities, such as the on-campus internship and the external placement.

This study revealed that such perceptions could evolve as early as during professional education.

\section{Conclusion}

The rich data that emerged from this multi-method study may assist clinical educators in manual medicine programs develop means of measuring professional confidence and fostering its development. One particularly promising area for educational intervention may be the promotion of a pro-active approach to professional learning.

\section{Competing interests}

The authors declare that they have no competing interests.

\section{Author details}

${ }^{1}$ School of Chiropractic and Sports Science, Murdoch University, Murdoch, Western Australia. ${ }^{2}$ School of Education, Murdoch University, Murdoch, Western Australia.

\section{Authors' contributions}

$\mathrm{MH}$ conducted the individual interviews. $\mathrm{MH}$ and SV performed the content analysis. All authors contributed substantially to the conception and design of the study, as well as to the critical revision of the paper. All authors approved the final manuscript.

\section{Funding}

There was no funding for this project.

Received: 15 October 2011 Accepted: 19 June 2012

Published: 19 June 2012

\section{References}

1. Moeller P: Clinical supervision: Guidelines for managing the problem student. J Allied Health 1984, 13:205-211. 
2. Hecimovich $M$, Volet S: Development of professional confidence in health education: Research evidence of the impact of guided practice into the profession. Health Educ 2011, 111(3):177-197.

3. Chickerella BG, Lutz WJ: Professional nurturance: preceptorships for undergraduate nursing students. Am J Nurs 1981, 81:107-109.

4. Harrell PL, Kearl GW, Reed EL, Grigsby DG, Caudill TS: Medical students' confidence and the characteristics of their clinical experiences in a primary care clerkship. Acad Med 1993, 68:577-579.

5. Morgan PJ, Cleave-Hogg D: Comparison between medical students' experience, confidence and competence. Med Educ 2002, 36:534-539.

6. Levy BT, Merchant ML: Factors associated with higher clinical skills experience of medical students on a family medicine preceptorship. Fam Med 2005, 37:332-340

7. Lai NM, Ramesh JC: The product of outcome-based undergraduate medical education: Competencies and readiness for internship. Singapore Med J 2006, 47(12):1053-1062.

8. Bartlett DJ, Lucy SD, Bisbee L, Conti-Becker A: Understanding the professional socialization of Canadian physical therapy students: A qualitative investigation. Physiother Can 2009, 61(1):15-25.

9. Spegman AM, Herrin S: Chiropractic interns' perceptions of stress and confidence. J Chiropr Educ 2007, 21(2):129-137.

10. Clayton RA, Henderson S, McCracken SF, Wigmore SJ, Paterson-Brown S: Practical experience and confidence in managing emergencies among preregistration house officers. Post Med J 2005, 81:396-400.

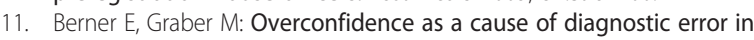
medicine. Am J Med 2008, 121(5A):S2-S23.

12. Rasch G: Probabilistic models for some intelligence and attainment tests. Copenhagen: Denmark Paedogogiske Institute; 1960 (Republished Chicago: The University of Chicago Press: 1980)

13. Rasch G: Probabilistic models for some intelligence and attainment tests. Chicago: The University of Chicago Press; 1980 (original work published in 1960).

14. Andrich D, Sheridan B, Luo R: Manual for the Rasch Unidimensional Measurement Model (RUMM2010). Perth, Western Australia: RUMM Laboratory; 2001.

15. Schwarzer R: Measurement of perceived self-efficacy. Psychometric scales for cross-cultural research. Berlin: Freie Universität Berlin; 1993.

16. Schwarzer R, Bäßler J, Kwiatek P, Schröder K, Zhang JX: The assessment of optimistic self-beliefs: Comparison of the German, Spanish, and Chinese versions of the General Self-Efficacy Scale. Int Rev Appl Psychol 1997, 46(1):69-88.

17. McCroskey JC, Beatty MJ, Kearney P, Plax TG: The content validity of the PRCA-24 as a measure of communication apprehension across communication contexts. Comm Q 1985, 33:165-173.

18. Braun V, Clarke V: Using thematic analysis in psychology. Qual Res Psychol 2006, 3(2):77-101

19. Schunk D: Modeling and attributional effects on children's achievement: A self-efficacy analysis. J Educ Psychol 1981, 73:93-105.

20. Freidman C, Gatti G, Elstein A, Franz T, Murphy G, Wolf F: Are clinicians correct when they believe they are correct? Implications for medical decision support. In Proceedings of the 10th World Congress on Medical Informatics. London: MEDINFO 2001; 2000:454-458.

21. Beyer S, Bowden EH: Gender differences in self-perceptions: convergent evidence from three measures of accuracy and bias. Pers Soc Psychol Bull 1997, 23:157-172.

22. Blanch DC, Hall JA, Roter DL, Frankel RM: Medical student gender and issues of confidence. Patient Educ Couns 2008, 72(3):374-381.

23. Besterfield-Sacre M, Moreno M, Shuman LJ, Atman CJ: Gender and ethnicity differences in freshmen engineering student attitudes: a crossinstitutional study. J Eng Educ 2001, 90(4):477-494

24. Busch T: Gender differences in self-efficacy and attitudes towards computers. J Educ Comput 1995, 12:147-158.

25. Minter RM, Gruppen LD, Napolitano KS, Gaugen PG: Gender differences in the self-assessment of surgical residents. Am J Surg 2005, 189:647-650.

26. Lind DS, Rekkas S, Bui V, Lam T, Beierle E, Copeland EM: Competency-based student self-assessment on a surgery rotation. J Surg Res 2002, 105:31-34.

27. Baxter N, Cohen R, McLeod R: The impact of gender on the choice for surgery as a career. Am J Surg 1996, 172:373-376.

28. Bolam H, Dodgson R: Retaining and supporting mature students in higher education. J Adult Cont Educ 2003, 8(2):179-194.
29. Hayes K, Feather A, Hall A, Sedgwick P, Wannan G, Wessier-Smith A, Green $T$, McCrorie P: Anxiety in medical students: is preparation for full-time clinical attachment more dependent upon differences in maturity or on educational programmes for undergraduate and graduate entry students? Med Ed 2004, 38:1154-1163.

30. Feil D, Kristian M, Mitchell N: Older medical students' performance at McGill University. Acad Med 1998, 73:98-100.

31. Donaldson J, Graham S: A model of college outcomes for adults. Adult Ed Qrtly 1999, 50(1):24-40

32. Holmes DR, Hodgson PK, Simari RD, Nishimura RA: Mentoring:Making the Transition From Mentee to Mentor. Circulation 2010, 121:336-340.

33. Ende J: Feedback in clinical medical education. JAMA 1983, 25:777-781

34. Pitney $W$, Ehlers $G$ : A grounded theory study of the mentoring process involved with undergraduate athletic training students. J Ath / Train 2004 39(4):344-351

35. Curtis N, Helion J, Domsohn M: Student athletic trainer perceptions of clinical supervisor behaviors: a critical incident study. J Athl Train 1998, 33:249-253

36. Bandura A: A Sociocognitive Analysis of Substance Abuse: An Agentic Perspective. Psychol Sci 1999, 10:214-217.

37. Flynn TW, Childs JD, Fritz JM: The audible pop from high-velocity thrust manipulation and outcome in individuals with low back pain. $J$ Manipulative Physiol Ther 2006, 29:40-45.

38. Cleland JA, Flynn TW, Childs JD, Eberhart S: The audible pop from thoracic spine thrust manipulation and its relation to short-term outcomes in patients with neck pain. J Manage Manipulative Physiol Ther 2007, 15 (3): 143-154

39. Mirtz TA, Hebert JJ, Wyatt LH: Attitudes of non-practicing chiropractors: a pilot survey concerning factors related to attrition. Chiropr Osteopat 2010, 18(29). doi:10.1186/1746-1340-18-29.

doi:10.1186/1472-6920-12-42

Cite this article as: Hecimovich and Volet: Tracing the evolution of chiropractic students' confidence in clinical and patient communication skills during a clinical internship: a multi-methods study. BMC Medical Education 2012 12:42.

\section{Submit your next manuscript to BioMed Central and take full advantage of:}

- Convenient online submission

- Thorough peer review

- No space constraints or color figure charges

- Immediate publication on acceptance

- Inclusion in PubMed, CAS, Scopus and Google Scholar

- Research which is freely available for redistribution 